\title{
Informing Implementers of Lean Strategy in Process Industries - The Central Role of Schedulers
}

\author{
Irit Alony and Peter Caputi, Faculty of Commerce, \\ Tim Coltman, Faculty of Health and Behavioural Sciences, \\ University of Wollongong, Woolongong, Australia
}

\section{iritalony@gmail.com; pcaputi@uow.edu.au; tcoltman@uow.edu.au}

\begin{abstract}
Lean strategy has been recognized for its benefits to discrete manufacturing industries worldwide. However, implementing Lean strategy in process industries has proven difficult. In an attempt to address this problem, this paper identifies scheduler's decisions as crucial to the successful execution of Lean strategy. The paper examines existing descriptions of schedulers and their roles, in search of their potential impact on this execution. Using a case study from the Australian steel industry, empirical evidence shows that schedulers are critical to the success of Lean strategy. Two paths of impact are suggested: (1) schedulers' role as negotiators and facilitators of business operations, and (2) schedulers' discretion and prioritization of business needs. The paper concludes with suggestions for further research on ways to support schedulers' execution of Lean strategy.
\end{abstract}

Keywords: Scheduling, Process industries, Lean strategy, Strategy execution, Schedulers role.

\section{Introduction}

Among production and manufacturing businesses, Lean strategy is widely recognized as being important to business success and competitive advantage (Lewis, 2000; MacDuffie, 1995; Pfeffer, 1994; Shah \& Ward, 2003). Lean strategy has successfully enabled businesses around the world to address customer demand, while maintaining high production volume (Ohno, 1988; Sohal \& Egglestone, 1994; Sriparavastu \& Gupta, 1997; White, Pearson, \& Wilson, 1999). This strategy reduces throughput times and customer-response times (Fullerton \& McWatters, 2001; White et al., 1999;), while paradoxically permitting (or in fact, requiring) lower inventory, contrary to traditional practice. However, not all industries have taken up this strategy to the same degree (Dennis \& Meredith, 2000). For example, the origins of Lean strategy are grounded in automotive manufacturing and other forms of discrete industry where assembly activities dominate (Holweg,

Material published as part of this publication, either on-line or in print, is copyrighted by the Informing Science Institute. Permission to make digital or paper copy of part or all of these works for personal or classroom use is granted without fee provided that the copies are not made or distributed for profit or commercial advantage AND that copies 1) bear this notice in full and 2) give the full citation on the first page. It is permissible to abstract these works so long as credit is given. To copy in all other cases or to republish or to post on a server or to redistribute to lists requires specific permission and payment of a fee. Contact Publisher@InformingScience.org to request redistribution permission.
2007). In these industries, value-add is gained through the assembly and handling of whole discrete components (e.g., computer assembly, clothing manufacturers, automotive industries, etc.), and they have been more successful than process industries at reducing waste and inventory levels (Abdullah \& Rajgopal, 2003; Dennis \& Meredith, 2000; Schonberger, 1982). In contrast, process industries add value by modify- 
ing the physical or chemical properties of materials. These industries lag behind discrete industries in the uptake of Lean strategy (Abdullah \& Rajgopal, 2003; Belvedere \& Grando, 2005; Dennis \& Meredith, 2000).

The difference in uptake between the two industry sectors suggests that process industries are innately unsuitable for the successful adoption of Lean strategy, but this is not the case. The steel industry is an example of a process industry that is a potential candidate for the adoption of Lean strategy, and several reports of successful adoptions and executions of Lean strategy in the steel industry exist (Abdulmalek \& Rajgopal, 2007; Dhandapani, Potter, \& Naim, 2004; Harrison, 2005; Storck \& Lindberg, 2007). These reports suggest that the steel industry can adopt at least some of the principles on which Lean strategy is based. However, these reports do not explain why Lean strategy is not accepted more widely in process industries, such as steel-making, chemical, paper, and oil industries.

Lean strategy varies from traditional production strategy in several ways. Primary differences are (Alony, 2010; Hopp \& Spearman, 2004; Monden, 1994; Ohno, 1988; Taylor \& Taylor, 2008; Womack \& Jones, 2003): (1) Lean adopts a customer-centric view as opposed to the more traditional cost-centric focus. Therefore, Lean prioritizes quick delivery rather than scale advantages. (2) Lean focuses on overall supply chain optimization rather than localized optimization. Therefore, emphasis is placed in the production of small batches and paced production (i.e. Kanbans).

(3) Lean focuses on continuous improvement, rather than episodic improvement and thus reduces levels of buffer inventory.

Lean is driven by a single strategic imperative, which is central for the successful execution of Lean strategy: that is, to maintain low levels of intermediate product inventory, also termed workin-process (WIP). Maintaining low WIP levels throughout the supply chain of a business is central to sustaining Lean strategy (Hopp \& Spearman, 2004). This requirement also represents the focal point of difficulty for process industries, as WIP levels are often used to buffer processrelated problems (Abdullah \& Rajgopal, 2003; Crama, Pochet, \& Wera, 2001).

A further difficulty in executing Lean strategy stems from the way WIP levels are controlled. WIP inventory levels are not controlled directly (Sterman, 1989). Rather, they result from indirect daily operational decisions regarding batch sizes, number of changeovers, and aspired inventory levels. These decisions are routinely addressed by schedulers (MacCarthy \& Wilson, 2001), often operating in teams that include planners and controllers (McKay \& Wiers, 2003). Consequently, the role and impact of schedulers on the enactment of Lean strategy warrants attention.

Another aspect commonly emphasized in Lean strategy is the need for collaboration between different organizational functions (Fraser, Harris, \& Luong, 2007; McLachlin, 1997; Womack \& Jones, 2003). In discrete industries, work is re-arranged to ensure that cells of related work are positioned in close proximity to each other: a term commonly known as cellular manufacturing (Yauch \& Steudel, 2002). Cellular manufacturing is typically not feasible for process industries, due to limitations of equipment size and capital investments (Shah, 2005). However, crossfunctional collaboration remains central to the successful adoption of Lean strategy. Since schedulers' work innately involves collaboration with the different functions (Berglund \& Guinery, 2008; Berglund \& Karltun, 2007; MacCarthy \& Wilson, 2001), the answer to the facilitation of cross-functional collaboration may involve them.

Previous studies have identified the importance of schedulers to operational activities and business financial performance (Berglund \& Guinery, 2008; Berglund \& Karltun, 2007; Fransoo \& Rutten, 1994; Jackson, Wilson, \& MacCarthy, 2004). For example, schedulers have been described as influencers and negotiators, problem anticipators and solvers, and key information nodes (Berglund \& Karltun 2007; Jackson et al. 2004). However, the critical role that schedulers play in the adoption of Lean strategy has not previously been highlighted. Schedulers were pre- 
dominantly studied in stable operational environments, that is, where new strategy implementations are not underway (Fransoo \& Rutten, 1994; MacCarthy \& Wilson, 2001; Jackson et al., 2004), and the link to strategy adoption has not been made explicitly. This study, therefore, extends existing literature by examining the supporting or impeding impact of schedulers on the enactment and sustainability of Lean strategy in a process industry.

This research address the question: What role do schedulers in the steel industry play in the enactment of Lean strategy, and how does it compare with schedulers' previously described roles?

To address this question, this paper first reviews existing literature on schedulers, and identifies the specific roles they play in organizations. Next, the paper describes the roles of schedulers in the steel industry during the implementation of Lean strategy, and compares it to the existing literature. The paper concludes that schedulers' roles extend beyond those previously described, and these roles have an important influence on the execution of Lean strategy in process industries.

\section{Schedulers and Scheduling Decisions}

Schedulers are responsible for bridging and synchronizing production capabilities and customer demand (Jackson et al., 2004; McKay \& Wiers, 1999). They regularly balance and trade-off conflicting requirements of timely delivery and capacity utilization (Cegarra 2008). When schedulers prioritize these requirements in alignment with Lean strategy, the strategy is successfully executed (van der Krogt, Geraghty, Salman, \& Little, 2010). Therefore, the enactment of Lean strategy depends on the way schedulers prioritize and trade-off conflicting requirements (Baker \& Scudder, 1990).

Despite schedulers' centrality and importance to production organizations, literature describing them in practice is relatively scarce (Berglund \& Karltun, 2007; Jackson et al., 2004). All studies of schedulers concur that their core responsibility is to provide an efficient sequence of production that addresses customer demand. However, these studies also contend that the human contribution of schedulers is essential and extends beyond a simple production sequencing role.

Schedulers perform other roles such as an information repository, problem anticipator and solver, as well as an interpersonal role that involves influencing and negotiating with other parties in the development and enactment of the production schedule.

These roles resulted from previous studies of schedulers. However, these studies have not covered an important set of circumstances: they have not examined schedulers' roles when a large scale, new strategy is proposed (Fransoo \& Rutten, 1994; MacCarthy \& Wilson, 2001; Jackson et al., 2004). This literature review therefore described schedulers' roles based on previous literature, and examines how these roles may affect the adoption of Lean strategy in process industries, and suggests that the potential influence schedulers may have on the execution of Lean strategy is significant.

\section{Schedulers' Roles}

Schedulers have three significant roles to play in their execution of Lean. They manage information, they handle problems, and they coordinate different business functions. The following three sub-sections describe these roles in more detail.

\section{Information node}

Schedulers perform the role of an information node, which means they (1) receive up-to-date information from various sources, (2) disseminate information to the production units, and ensure that information is accessible and visible (Berglund \& Karltun 2007; Jackson et al., 2004), and (3) 
manipulate the information they use in order to make it fit reality. Schedulers filter information using "a range of behaviors, including ... selection, smoothing out, verification, [and] interpolation" (Jackson et al., 2004, p. 543). These behaviors demonstrate the close link between schedulers and information concerning plant operation.

Since schedulers regularly manipulate information used for their own decisions and the decisions of others, they have potential influence on the enactment of espoused strategy. For example, schedulers can use their own discretion to evaluate the production situation and round-up ordered product quantities, and justify large batches that maintain high WIP levels. Thus, each scheduler's unique interpretation of available information can be counter to the principles of Lean and potentially hinder the execution of Lean strategy.

\section{Problem anticipator and solver}

Schedulers are constantly aware of the production situation. Their understanding of how potential problems can affect the execution of the schedule guides them to engage in problem prevention or minimization of impact (McKay \& Wiers, 2003; Jackson et al., 2004). Schedulers are expected to solve problems resulting from unexpected events, and to coordinate different production units (Berglund \& Karltun, 2007).

In some cases, schedulers engage in problem-solving for a considerable amount of their time (Berglund \& Karltun, 2007). From an operational perspective, scheduling may be viewed as a problem-solving activity, rather than a sequencing activity (McKay \& Wiers, 1999; Jackson et al., 2004). Schedulers use various techniques and options to handle interruptions, such as re-

allocation of resources and re-arrangement of sequencing details (Fransoo \& Wiers, 2006). However, schedulers often need to sacrifice some goals in order to achieve others (Cegarra, 2008; Guinery \& MacCarthy, 2009). Thus, scheduling goals are not necessarily static and clearly defined in the schedulers' mind; rather, they are contextual, situation-dependent, and constructed as the situation unfolds.

The need to address scheduling execution problems by prioritizing business goals is a potential area of influence regarding the execution of Lean strategy. Unless schedulers consistently prioritize low WIP levels and small batches in their problem-solving, the successful execution of Lean strategy is under great risk.

\section{Negotiator and influencer}

Schedulers expend time, effort, and attention to develop interpersonal relationships with the stakeholders involved in production, delivery, and customer service (Berglund \& Karltun, 2007; Jackson et al., 2004). Such relationships facilitate the execution of the schedule, as schedulers typically do not have formal authority over these functions (Berglund \& Guinery, 2008). Schedulers use bargaining and favors, and rely on stakeholders' trust and respect to influence their actions (Jackson et al., 2004). As part of this role, schedulers often engage in negotiated group decision-making, where different parties often have conflicting goals and agendas (Guinery \& MacCarthy, 2009).

Schedulers' influence on negotiations can impact the success of the adoption of Lean strategy, as these negotiations often concern balancing the demands of production efficiency (leading to large batches) and customer demand (leading to smaller batches). Naturally, schedulers are not the only ones having an impact on negotiations. However, since the schedulers exert their influence in an attempt to achieve the most optimal balance between business' demands, their support of Lean strategy can greatly support its successful execution. 


\section{Executor of a New Strategy - The Gap}

Although the scheduling team is critical to the determination of the processing sequence, batch sizes, and inventory levels, no academic study has previously examined their adjustment to a new strategy, such as Lean strategy (Sheldon, 2005). While computerized support to schedulers transitioning into Lean strategy is possible (e.g., van der Krogt et al., 2010), ultimately it is up to the human scheduler to make decisions that either accept computerized recommendations for scheduling decisions (and thus, support Lean strategy), or reject them. This study addresses this gap by examining schedulers' role in the implementation of Lean strategy.

\section{Research Approach}

The importance of schedulers' decisions to the operations of a production and manufacturing organization suggests scheduling practices critically influence the successful implementation of Lean strategy. However, scheduling in the context of adopting a new strategy has not been previously studied. Therefore, to investigate the role of schedulers in their adoption of Lean strategy in process industries, case study research was chosen. Case study research is particularly valuable when the intention is to examine phenomena in its natural setting (Meredith, 1998), and it is a powerful approach that can provide a rich set of data on real-world practice (Eisenhardt, 1989; Voss, Tsikriktsis, \& Frohlich 2002).

Case studies are used to explain phenomena when the researcher has limited, if any, control over events, behaviors, and conditions, and when the focus is on contemporary and contextual events (Yin 2003). In addition, according to Yin (2003), case studies are appropriate when the research seeks to address "how" and "why" questions. The questions of this research are mainly interested in how and why Lean strategy is accepted or rejected in the steel industry, therefore suggesting case research is appropriate.

Case studies, much like other qualitative research methods, do not require a large number of participants. In fact, some research methods discourage large numbers of participants (Sanders, 1982), as the amounts of data become overwhelming, and hinder rigorous analysis and understandings. A common guideline for qualitative data collection is saturation (Glaser \& Strauss, 1967): a point in which no new qualitative categories emerge, even when new sources are explored. For this reason, less than twenty participants were involved in this study. Their contributions were analyzed in great detail to uncover meaningful categories that address the research question.

A case study does not always describe a situation that can be easily applied to other circumstances. In other words, a case study cannot be easily generalized. The ability to generalize the results of a case study is captured by its external validity. To address this aspect of the case study's rigor (i.e., its external validity), researchers are required to provide a clear rationale for selecting the research site, and "ample details on the case study context to allow the reader to appreciate the researchers' sampling choices" (Gibbert, Ruigrok, \& Wicki, 2008, p. 1468). These details are discussed next.

\section{Research Site Selection}

The site selected for this study involved a large Australian steel manufacturer. The organization has attempted to implement Lean strategy in several units over the past few years. The organization invested great effort, time, and resources in preparing for this implementation. The preparation included over six months of training (both internal and external), recruitment of Lean strategy experts from around the world, and executive management support (Alony, 2010). Examining the issues raised in such an implementation provides an opportunity to gain insight into the innate difficulties involved in the adoption of Lean strategy in process industries. Lessons from 
this attempt, as well as the accounts of current schedulers were used to construct a holistic view of the role that schedulers play when Lean strategy is executed in process industries.

\section{Research Procedures}

Eight key implementers were interviewed about their views of the implementation. The interviewees included all organizational levels: executive managers, middle managers, and line managers. Archival documents relevant to this implementation were examined as well, in order to corroborate interviewee testimonies. In addition, scheduling practices in two of the organization's business units were examined in order to gain a contemporary perspective on the roles of schedulers. This examination was conducted through a second set of interviews, which examined current influences on scheduling practices, by interviewing eight key scheduling-team members from two different business units. Furthermore, documents relevant to current scheduling practices were examined, to corroborate and extend the schedulers' testimonies.

The two interview sets were one year apart. The first set focused on an attempt to implement Lean strategy several years prior to the time of the interviews. Participants were selected from various organizational levels, and a range of roles within the Lean strategy implementation team.

The second set was concerned with contemporary scheduling practices, and factors influencing them. Participants were selected from various functions within a scheduling team (i.e., planners, schedulers, and controllers) from two different production units. Table 1 presents a summary of this study's participants.

A thematic analysis of the findings from both sets sought to identify recurring patterns and themes relating to the factors that support and impede the execution of Lean strategy. The analysis reveals the importance of schedulers for the successful implementation and execution of Lean strategy.

Table 1: Participants summary

\begin{tabular}{|c|c|c|c|c|}
\hline \multicolumn{2}{|c|}{ Lean implementation team } & \multicolumn{3}{c|}{ Current schedulers } \\
\hline \multicolumn{2}{|c|}{ Managerial level } & & Unit A & Unit B \\
\hline Top management & 3 & Planner & 1 & 1 \\
\hline $\begin{array}{c}\text { Middle } \\
\text { management }\end{array}$ & 2 & Scheduler & 3 & 2 \\
\hline Line management & 3 & Controller & 1 & - \\
\hline
\end{tabular}

\section{Findings - Schedulers as Strategy Executor}

The findings in this section demonstrate that schedulers play an important role in the execution of Lean strategy in the steel manufacturing organization. The findings are presented based on their sources. Indirect evidence those found in testimonies of Lean strategy implementers are presented first. Direct schedulers' accounts of their own roles that indicate their importance to the successful execution of Lean strategy follow. The congruence amongst testimonies - from both direct and indirect sources - highlights the so-far ignored importance of schedulers in the implementation process of Lean strategy in the steel industry.

\section{Indirect Testimonies}

In addition to the schedulers' roles described in literature, the schedulers in this organization were found to be central to the successful execution of the production strategy. This centrality of the schedulers was pointed out by several individuals involved in the implementation of Lean strat- 
egy. These individuals, their roles, and their credibility are described along with their testimo-

nies. Table 1 summarizes these testimonies and their credibility.

\section{Program director}

Cameron, the director of the program, has managed several organizational changes in the same organization before and after this attempt to implement Lean strategy. He used the lessons learned from this implementation in subsequent changes, and thus his insight was considered as credible. His view on the role of schedulers is shown in this quote:

[Successful changes here are] run from the middle. These [large] companies are managed from the middle. The people that would make Lean happen, they are typically master schedulers and the level below them. I think they are the key. [If you find] common ground with them, it will work for sure. [Otherwise], as soon as their boss loses interest [in Lean] or their boss moves, it's going to struggle. (Cameron, program director)

Cameron is referring to the need to gain schedulers' support for, and agreement to, Lean strategy, as they have the power to "run" the large organization studied. He sees them as being central to the sustainability of Lean strategy as long as they intrinsically agree with the strategy, and are not driven by the authority of their boss.

\section{Program manager}

Cameron's view was supported by other members of the implementation team, when schedulers were referred to as part of middle management. Vincent, a manager of the implementation program, worked daily with schedulers, line managers, and other floor personnel in order to implement Lean strategy. He contends that schedulers were at the same time the most important, and the most difficult, group to convince: "[Who can support the success of Lean strategy?] It's the middle. It's convincing the people who had to make it happen... that was our hardest group of people to convince" (Vincent, project manager).

This testimony supports Cameron's view, that people in "the middle" enact Lean strategy. It also highlights that it was both necessary and difficult to convince these people.

\section{Program sponsor}

Another testimony supporting the view that schedulers were difficult to convince is given by the program sponsor, Ross. As a senior member, he was intimately involved in the process of introducing Lean strategy to the various organizational members of the unit. He witnessed the different reactions to this strategy, and concludes: "The biggest problem was middle management. Middle management hated to see any unit stop... they didn't like it" (Ross, program sponsor).

This testimony explains the source of conflict between Lean strategy and process-industry managers: the reluctance to stop machines from processing. The reasons for this reluctance have been discussed in details elsewhere (Alony, 2010). The indirect testimonies are summarized in Table 2. 
Table 2: Findings Summary - Direct Testimonies

\begin{tabular}{|c|c|c|}
\hline $\begin{array}{l}\text { INTER- } \\
\text { VIEWEE }\end{array}$ & CREDIBILITY & TESTIMONY \\
\hline $\begin{array}{l}\text { Program } \\
\text { Director } \\
\text { (Cam- } \\
\text { eron) }\end{array}$ & $\begin{array}{l}\text { Extensive change management } \\
\text { experience in the organization }\end{array}$ & $\begin{array}{l}\text { Schedulers are critical to sustain the execution of Lean } \\
\text { strategy in the steel manufacturing organization } \\
\text { Schedulers are permanent in the organization, unlike top } \\
\text { managers }\end{array}$ \\
\hline $\begin{array}{l}\text { Program } \\
\text { Manager } \\
\text { (Vincent) }\end{array}$ & $\begin{array}{l}\text { Extensive experience in work- } \\
\text { ing with various organizational } \\
\text { members during the imple- } \\
\text { mentation of Lean strategy }\end{array}$ & $\begin{array}{l}\text { - Schedulers are critical to sustain the execution of Lean } \\
\text { strategy in the steel manufacturing organization } \\
\text { - Schedulers have a direct impact on the execution of Lean } \\
\text { strategy } \\
\text { - Schedulers were difficult to convince to adopt Lean strat- } \\
\text { egy }\end{array}$ \\
\hline $\begin{array}{l}\text { Program } \\
\text { Sponsor } \\
\text { (Ross) }\end{array}$ & $\begin{array}{l}\text { Frequent encounters with vari- } \\
\text { ous organizational members } \\
\text { during the implementation of } \\
\text { Lean strategy }\end{array}$ & $\begin{array}{l}\text { Dchedulers were difficult to convince to adopt Lean strat- } \\
\text { egy }\end{array}$ \\
\hline
\end{tabular}

In addition to testimonies of implementers of Lean strategy, schedulers' accounts of their own role also demonstrate that they can strongly influence the successful execution of this strategy. These accounts are described next.

\section{Schedulers' Direct Accounts}

This section examines direct testimonies of schedulers explaining their role. These testimonies show not only the importance of schedulers to the enactment of a strategy, but also the methods they use to enact it. First, the importance of explaining the strategy to the scheduler is described by the planner, who has a greater overview of the required output:

Once we [management] have made the decision at the planning level, I take the outputs, [the] document that says "this is what we should run" and talk with the scheduler. I make sure that he understands the direction for him, and the reasons why we have to stop the [production] line - because we are making too much inventory and it will blow the budget, for example. (Lee, planner and scheduler, Unit A)

The scheduler must understand the overall strategy and the "big picture" because of the scheduler's influence on how targets are achieved. The fact that top management and the planner dedicate time to routinely brief the scheduler and explain the underlying reasoning behind their decisions indicates that the scheduler's understanding of the strategy is important.

Another indication of the role of the scheduler as a strategy executor is the schedulers' confidence that they can achieve targets dictated to them by planning level: "[If] the [planning schedule] says you should be able to achieve it [then you] make it happen (Fred, master scheduler, Unit A).

The scheduler in this quote demonstrates his belief that he can and should achieve the targets posed by the overall plan. He sees it as his role to find a way to enact the plan.

Although they are required to enact the production schedule, schedulers often do not have formal authority over the different functions of production, maintenance, or sales, as evident in these quotes:

You can develop the best plan in your head, [but] you don't own the line and you don't have any direct control over lines. You have to sell it to someone and get them to sign off on something weird with this line, [like] stop a line. (Fred, master scheduler, Unit A) 
These quotes show that schedulers are responsible for enacting the goals set by higher management levels. The scheduler receives the planned schedule, and the production objectives that are set on an aggregated level by the plant's management. Schedulers then translate these objectives into daily operations. Often, the aggregated level does not take into account the low-level operational constraints, such as changeover rules, maintenance problems, and urgent orders. The scheduler, who maintains an overview of the plant's current state in terms of resources and constraints, is required to understand the strategy and the operational implications derived from it in order to execute it.

To execute a business strategy and achieve targets required, schedulers use "levers". These "levers", or alternative courses of action, are described in the following quote:

[Levers are] usually about pushing export out or in, that is one lever that you can use. Recommending that we cut domestic demand, that's another lever. If we have too much inventory, we can recommend stopping a unit. There is point-of-production change as well: I can get another site to help me make my orders. (Lee, planner and scheduler, Unit A)

This quote demonstrates that schedulers may take various actions (or draw upon various "levers") in order to resolve a problem. One lever is modifying the amount sold as export. Domestic orders can be prioritized over export, and thus capacity can be used primarily to address domestic rather than export orders. In contrast, excess inventory can be released to export, thus reducing inventory levels. Another way to reduce, or avoid excess, inventory levels is by stopping production. If demand exceeds supply, schedulers can also restrict future demand by setting the quantities that customer service teams are allowed to sell. Finally, another way to address excess demand is by getting products produced in another plant. The impact of the "lever" (or alternative) chosen on the execution of Lean strategy is addressed in the discussion.

The importance and role of the scheduler reflected in the direct testimonies are summarized in Table 3.

Table 3: Summary of direct testimonies on schedulers' role and importance

- Scheduler's understanding of the overall strategy is important

- A scheduler should and can enact the production plan

- A scheduler enacts the production plan by negotiating with other organizational functions

- A scheduler enacts the production plan and achieves business targets by utilizing various courses of action

Current schedulers were not actively concerned with executing Lean practices, such as reduction of batch sizes and reduction of inventory. Rather, the schedulers were focused on achieving their targets, with no reference to whether their actions are aligned with Lean strategy.

\section{Discussion}

The important role of schedulers in the adoption and execution of Lean strategy was explicitly identified by individuals involved in implementing Lean strategy in the steel manufacturing organization. None of the sources indicated that the schedulers' role as an information node contributed to this influence. However, the indirect evidence pointed to the importance of the schedulers due to their permanent involvement in production operations (unlike top managers, who are more transient in the organization), as well as their direct influence on actual production. This 
finding begs further examination in other process industries, to examine how their roles compare with literature when Lean strategy implementation is underway.

Although the schedulers did not provide explicit evidence about their role as strategy executors, they did support the notion that strategy enactment is up to them. However, their testimonies shed light on a more fundamental question: how do schedulers impact the execution of Lean strategy? The answer to this question can be interpreted from the description of their role.

Schedulers' testimonies described the way they execute business strategies: (1) through negotiation and influence on other organizational functions, and (2) through using alternative courses of action (i.e., "levers"), in an attempt to enact a production plan. These ways are discussed in more detail next.

\section{The Scheduler as Negotiator and Influencer}

In their role as negotiators, schedulers facilitate the execution of production plans. Since schedulers cannot impose their production plans on the machine owners, they use negotiation to influence production. Thus far, this is similar to the previously described roles of schedulers. Previous literature identifies the importance of interpersonal relationships to the operation of schedulers (Berglund \& Karltun, 2007; Jackson et al., 2004). This research found support similar to these studies, finding schedulers often lack formal control over the other functions they work with. They therefore use relationships in their collaboration with other business functions as a source of influence.

However, this research draws attention to another aspect of this collaboration with other organizational functions - the impact of collaboration on Lean strategy execution. Schedulers' negotiations with the different organizational functions (production, sales, and logistics) make these functions aware of each other's needs and constraints. They explain to the various functions the impact of their actions on overall business success. For example, schedulers explain to production managers that if they continue to overproduce, they will exceed budget. This increased awareness of cross-functional needs and constraints facilitates cross-functional collaboration, which is otherwise difficult to achieve in the steel industry.

While previous studies of Lean strategy emphasize the importance of cohesive relationships among cross-functional team members (e.g., Fraser et al., 2007; McLachlin, 1997), this study emphasizes the importance of schedulers, as the facilitators of cross-functional collaboration. Cross-functional collaboration is achieved in discrete industries by restructuring the organization into product-based cells, rather than functional departments. However, this study suggests that schedulers are particularly critical to this collaboration in the steel industry, more so than in discrete industries, since cellular manufacturing and work teams cannot be implemented in the steel industry (Belvedere \& Grando, 2005; Shah, 2005; Shah \& Ward, 2007). The collaboration between the different functions has to be facilitated by a central position, which holds an overview and an understanding of the entire operation. Namely, this collaboration is facilitated through schedulers.

\section{Schedulers' Alternatives Selection}

The schedulers described the way they address problems posed by conflicts between business targets and reality: by utilizing various alternative courses of action, or "levers". However, different levers lead to different side-effects, and these side-effects influence strategic alignment. For example, one lever described is making a recommendation to stop production in order to avoid a high inventory level. Using this lever supports Lean principles. However, schedulers may also export excess inventory for a lower cost to relieve inventory levels. This practice is not as closely aligned with Lean principles, since it encourages overproduction (i.e., production be- 
yond the requested amount). Thus, the scheduler may be able to achieve the same target, but in different ways, which differ in their degree of alignment with Lean strategy.

This role differs from the role of problem solver and anticipator, as the schedulers do not solely anticipate and solve problems relating to the schedule, but also problems in achieving the strategy prescribed by higher management.

Schedulers regularly use their discretion to prioritize different needs. Previous studies acknowledge that schedulers determine the priorities of objectives and make decisions regarding tradeoffs (Cegarra, 2008). This prioritization is critical to the enactment of Lean strategy, as it determines whether level scheduling is achieved, as required by Lean strategy (Naylor, Naim, \& Berry, 1999). This prioritization depends solely on schedulers' discretion. Under Lean strategy, schedulers are required to prefer small batches and low inventory levels. When they do not maintain this prioritization, Lean strategy is not sustained: inventory levels rise and lead times extend.

These priorities contradict traditional priorities in the steel industry, as demonstrated in this study, and as generally found in process industries (Fransoo \& Rutten, 1994). Schedulers play a critical role in the steel industry, as they can either follow, or change, this priority. Schedulers make trade-offs between batch sizes and lead times, which are at the centre of Lean strategy, and must align them with this strategy to enable its successful execution.

\section{Limitations}

This study is based on a single company, which has its own set of practices, history, shared understandings, and economic conditions. These aspects suggest that results may not be transferrable to other steel manufacturers. Furthermore, the results are not necessarily generalizable to other process industry manufacturers. Nonetheless, the findings presented have a strong intuitive and conceptual appeal. Despite organizational idiosyncratic characteristics, the findings presented provide sound grounding for future work that is amenable to quantitative verification.

\section{Conclusion and Further Research}

This research sought to understand the role schedulers play in the steel industry, and the impact of this role on the adoption and execution of Lean strategy. This study explicitly shows the centrality of schedulers to the successful execution of a strategy. The study highlighted the importance of schedulers for the enactment of Lean strategy, and sought to understand the nature of their impact on its adoption. The study examined previously described roles of schedulers, and identified additional roles that were evident in the context of Lean strategy execution in the steel industry.

Using a case-study methodology, this study found that schedulers influence the adoption of Lean strategy in the steel industry based on their facilitation of cross-functional collaboration. In addition, schedulers' routine prioritization can impact the execution of Lean strategy. Since schedulers can choose alternatives to resolve problems, they can impact the alignment of the operation with Lean strategy.

Despite the limitations of this study, which drew on a single organization and relied on retrospective and indirect evidence, it provides valuable insights into the factors that impede the steel industry from adopting Lean strategy. This study extends on existing operations management literature by highlighting the importance of schedulers to the enactment of Lean strategy, which has not previously been acknowledged.

Further research on this matter can provide academics and practitioners with a greater understanding not only of the problems faced by schedulers when Lean strategy is introduced into a process-industry company, but also with better strategies for addressing this problem. One area that is of clear importance to individual decision-making in organizational context is the area of 
organizational and corporate culture (Deal \& Kennedy, 1982; Kotter \& Heskett, 1992). While changing organizational culture is neither simple nor quick (Cameron \& Quinn, 1999), corporate culture can provide the support necessary for decisions that deviate from the status-quo. This aspect has not been previously addressed as in most large organizations, a corporate-wide support for a new strategy is generally difficult to achieve. However, evidence of its impact on strategy execution and success can encourage top-management buy-in of such adoption.

The IS community can greatly support the alignment of schedulers' decisions with Lean strategy, by developing ICT tools that simulate the outcomes of traditional decisions versus the outcomes of decisions aligned with Lean strategy. In particular, simulated visualizations can greatly impact individual decision making, as visual cues systematically affect decisions (Carter, Kaufmann, \& Michel, 2007; Hogarth, 1987). Thus, visual decision-support tools present an opportunity to inform schedulers as they go through the adoption of Lean strategy.

\section{Acknowledgements}

This research has been supported by a linkage program grant from the Australian Research Council (ARC). The views expressed here are solely those of the authors. The authors wish to thank Albert Munoz, Dr Trevor Spedding, Dr. Peter Robertson and Omar Devlin for their contribution to discussions and the direction of the paper.

\section{References}

Abdullah, F., \& Rajgopal, J. (2003). Lean manufacturing in the process industry. Proceedings of the IIE Research Conference, CD-ROM, Portland, OR, IIE, Norcross, GA.

Abdulmalek, F. A., \& Rajgopal, J. (2007). Analyzing the benefits of lean manufacturing and value stream mapping via simulation: A process sector case study. International Journal of Production Economics, 107(1), 223-236.

Alony, I. (2010). Human influence on the adoption of Lean strategy in the process industries: A case study of an Australian steel-manufacturer. School of Information Systems \& Technology. Wollongong, University of Wollognong. Manuscript submitted for publication.

Baker, K. R., \& Scudder, G. D. (1990). Sequencing with earliness and tardiness penalties: a review. Operations Research, 38(1), 22-36.

Belvedere, V., \& Grando, A. (2005). Implementing a pull system in batch/mix process industry through Theory of Constraints: A case-study. Human Systems Management, 24(1), 3-12.

Berglund, M., \& Guinery, J. (2008). The influence of production planners and schedulers at manufacturing and commercial interfaces. Human Factors and Ergonomics in Manufacturing, 18(5), 548-564.

Berglund, M., \& Karltun, J. (2007). Human, technological and organizational aspects influencing the production scheduling process. International Journal of Production Economics, 110(1-2), 160-174.

Cameron, K. S., \& Quinn, R. E. (1999). Diagnosing and changing organizational culture. Reading, MA: Addison-Wesley.

Carter, C. R., Kaufmann, L., \& Michel, A. (2007). Behavioral supply management: A taxonomy of judgment and decision-making biases. International Journal of Physical Distribution \& Logistics Management, 37(8), 631-669.

Cegarra, J. (2008). A cognitive typology of scheduling situations: A contribution to laboratory and field studies. Theoretical Issues in Ergonomics Science, 9(3), 201-222.

Chatman, J. A., \& Jehn, K. A. (1994). Assessing the relationship between industry characteristics and organizational culture: How different can you be? Academy of Management Journal, 37(3), 522-553. 
Crama, Y., Pochet, Y., \& Wera, Y. (2001). A discussion of production planning approaches in the process industry. Working Paper, University of Lie'ge.

Deal, T. E., \& Kennedy, A. A. (1982). Corporate cultures. Reading, MA; Addison-Wesley.

Dennis, D. R., \& Meredith, J. R. (2000). An analysis of process industry production and inventory management systems. Journal of Operations Management, 18(6), 683-699.

Dhandapani, V., Potter, A. \& Naim, M. (2004). Applying lean thinking: A case study of an Indian steel plant. International Journal of Logistics, 7(3), 239-250.

Eisenhardt, K. M. (1989). Building theories from case study research. Academy of Management Review, 14(4), 532-550.

Fransoo, J. C., \& Rutten, W. (1994). A typology of production control situations in process industries. International Journal of Operations and Production Management, 14(12), 47-47.

Fransoo, J. C., \& Wiers, V. C. S. (2006). Action variety of planners: Cognitive load and requisite variety. Journal of Operations Management, 24(6), 813-821.

Fraser, K., Harris, H., \& Luong, L. (2007). Team-based cellular manufacturing: A review and survey to identify important social factors. Journal of Manufacturing Technology Management, 18(6), 714-730.

Fullerton, R. R., \& McWatters, C. S. (2001). The production performance benefits from JIT implementation. Journal of Operations Management, 19(1), 81-96.

Gibbert, M., Ruigrok, W., \& Wicki , B. (2008). What passes as a rigorous case study. Strategic Management Journal, 29(13), 1465-1474.

Glaser, B. G., \& Strauss, A. L. (1967). The discovery of grounded theory: Strategies for qualitative research. Aldine.

Guinery, J., \&MacCarthy, B. (2009). Managing key interfaces in production planning and control. Production Planning and Control, 20(1), 40-56.

Harrison, J. (2005). Running steel "lean". Iron \& Steel Technology, 2(12), 88-96.

Hogarth, R. M. (1987). Judgement and choice: The psychology of decision. New York: John Wiley \& Sons.

Holweg, M. (2007). The genealogy of lean production. Journal of Operations Management, 25(2), 420437.

Hopp, W. J., \& Spearman, M. L. (2004). To pull or not to pull: What is the question? [Commissioned paper] Manufacturing \& Service Operations Management, 6(2).

Jackson, S., Wilson, J. R., \& MacCarthy, B. L. (2004). A new model of scheduling in manufacturing: Tasks, roles, and monitoring. Human Factors, 46(3), 533.

Kotter, J. P., \& Heskett, J. L. (1992). Corporate culture and performance. Free Press.

Lewis, M. A. (2000). Lean production and sustainable competitive advantage. International Journal of Operations and Production Management, 20(8), 959-978.

MacCarthy, B. L., \& Wilson, J. R. (2001). Human performance in planning and scheduling. CRC Press.

MacDuffie, J. P. (1995). Human resource bundles and manufacturing performance: Organizational logic and flexible production systems in the world auto industry. Industrial \& Labor Relations Review, 48(2), 197-221.

McKay, K. N., \& Wiers, V. C. S. (1999). Unifying the theory and practice of production scheduling. Journal of Manufacturing Systems, 18(4), 241-255.

McKay, K. N., \& Wiers, V. C. S. (2003). Planning, scheduling and dispatching tasks in production control. Cognition, Technology \& Work, 5(2), 82-93.

McLachlin, R. (1997). Management initiatives and just-in-time manufacturing. Journal of Operations Management, 15(4), 271-292. 
Informing Implementers of Lean Strategy

Meredith, J. (1998). Building operations management theory through case and field research. Journal of Operations Management, 16(4), 441-454.

Naylor, B. J., Naim, M. M., \& Berry, D. (1999). Leagility: Integrating the lean and agile manufacturing paradigms in the total supply chain. International Journal of Production Economics, 62(1-2), 107-118.

Ohno, T. (1988). Toyota production system: Beyond large-scale production. Productivity Press.

Pfeffer, J. (1994). Competitive advantage through people: Unleashing the power of the work force. Harvard Business School Press.

Sanders, P. (1982). Phenomenology: A new way of viewing organizational research. Academy of Management Review, 7(3), 353-360.

Schein, E. H. (2004). Organizational culture and leadership. Jossey-Bass.

Schonberger, R. J. (1982). The transfer of Japanese manufacturing management approaches to US industry. The Academy of Management Review, 7(3), 479-487.

Shah, N. (2005). Process industry supply chains: Advances and challenges. Computers and Chemical Engineering, 29(6), 1225-1236.

Shah, R., \&Ward, P. T. (2003). Lean manufacturing: Context, practice bundles, and performance. Journal of Operations Management, 21(2), 129-149.

Sheldon, D. H. (2005). World class master scheduling: Best practices and lean Six Sigma continuous improvement. J. Ross Publishing.

Sohal, A. S., \& Egglestone, A. (1994). Lean production: Experience among Australian organizations. International Journal of Operations and Production Management, 14, 35-35.

Sriparavastu, L., \& Gupta, T. (1997). An empirical study of just-in-time and total quality management principles implementation in manufacturing firms in the USA. International Journal of Operations and Production Management, 17, 1215-1232.

Sterman, J. D. (1989). Modeling managerial behavior: Misperceptions of feedback in a dynamic decision making experiment. Management Science, 35(3), 321-339.

Storck, J., \& Lindberg, B. (2007). A lean production strategy for hot charge operation of a steel mill. IET International Conference on Agile Manufacturing.

van der Krogt, R. J., Geraghty, J., Salman, M. R., \& Little, J. (2010). On supporting Lean methodologies using constraint-based scheduling. Journal of Scheduling, 13(4), 301-314.

Voss, C., Tsikriktsis, N., \& Frohlich, M. (2002). Case research in operations management. International Journal of Operations and Production Management, 22(2), 195-219.

White, R. E., Pearson, J. N., \& Wilson, J. R. (1999). JIT manufacturing: A survey of implementations in small and large US manufacturers. Management Science, 45(1), 1-15.

Womack, J. P., \& Jones, D. T. (2003). Lean thinking: Banish waste and create wealth in your corporation. New York: Free Press.

Yauch, C. A., \& Steudel, H. J. (2002). Cellular manufacturing for small businesses: Key cultural factors that impact the conversion process. Journal of Operations Management, 20(5), 593-617.

Yin, R. K. (2003). Case study research: Design and methods. Thousand Oaks, California: Sage Publications. 


\section{Biographies}

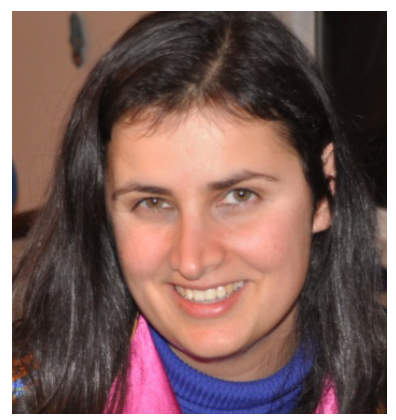

Irit Alony has been an academic teaching and researching in areas of information systems, management, and organisational behaviour since 2006. Irit has developed research interests in the following areas: organisational culture, human decision making, affect and emotions in the workplace, and organisational psychology. Irit is also developing research strengths in areas of qualitative methods. Irit has recently started her $\mathrm{PhD}$ on organisational turnover prediction in the University of Wollongong in Australia.

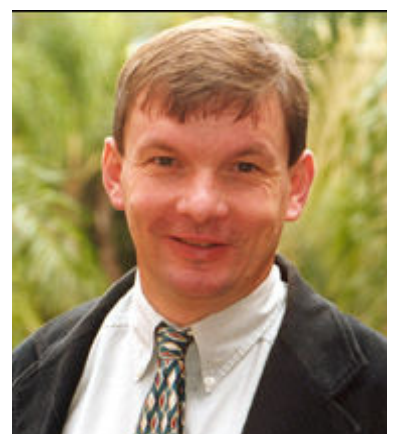

Tim Coltman is a Professor at the University of Wollongong, Australia. He received his $\mathrm{PhD}$ in strategic management from the Australian Graduate School of Management and his research has appeared in many books and journals such as: California Management Review, Journal of Information Technology, Journal Strategic Information Systems, European Journal of Information Systems, Journal of Business Research, Journal Supply Chain Management, Journal Business Logistics and Communications of the ACM.

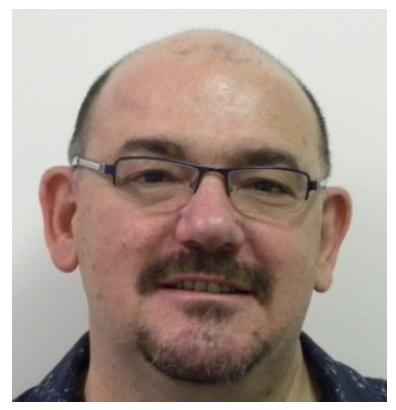

Peter Caputi is an Associate Professor in the School of Psychology at the University of Wollongong. His research interests include psychological determinants of IT/IS adoption. A/Prof has published over 100 peer-reviewed journal articles, book chapters and conference papers. He has published his research in Behaviour \& Information Technology, British Journal of Educational Technology and Computers in Human Behavior. 